\title{
Influence of structure zone model parameters on the electrical properties of $\mathrm{ZnO}: \mathrm{Al}$ sol gel coatings
}

\author{
T. Schuler ${ }^{\text {b }}$, T. Krajewski ${ }^{\text {a }}$, I. Grobelsek ${ }^{\text {a }}$, M.A. Aegerter ${ }^{\text {a,* }}$ \\ ${ }^{a}$ Leibniz-Institut für Neue Materialien (INM), Saarbruecken, Germany \\ ${ }^{\mathrm{b}}$ Schott Glas, Mainz, Germany
}

\begin{abstract}
Structure zone models (Movchan Demchishin, Thornton, etc.) have been proposed to predict the morphology of metal and metal oxide films produced by PVD or CVD processes. An original model was proposed for metal oxide coatings made by the sol gel process, based on a thorough experimental study of the microstructure of many coatings either obtained at INM or reported by other laboratories. The different morphologies granular, layered, columnar were described in terms of a parameter $q$ ICS/SLT, where ICS is a so called "intrinsic crystallite size" and SLT is the single layer thickness and the homologous temperature $T_{\mathrm{H}} T_{\text {Sintering }} / T_{\text {Melting. The influence of these }}$ morphologies and parameters on the electrical properties of transparent conducting $\mathrm{ZnO}$ :Al coatings is reported.
\end{abstract}

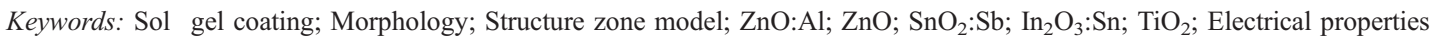

\section{Introduction}

Several structure zone models (SZM) have been proposed and refined since 1969 by several authors [1-6] addressing the morphology of thin metal and metal-oxide films produced by physical vapor deposition (PVD) techniques like evaporation [1] and sputtering [2] as well as by chemical vapor deposition (CVD) techniques like combustion CVD [5] and plasma-enhanced CVD [6]. A model for films produced by the sol-gel technique exemplified mostly for $\mathrm{ZnO}: \mathrm{Al}$ (AZO) has been proposed by us recently [7], but no direct comparison of the influence of the model parameters on the electric properties of such coatings has been reported, although it is known that the morphology strongly affects their performance.

The paper presents first a summary of the microstructures obtained for transparent conducting $\mathrm{ZnO} \mathrm{Al}$ (AZO) coatings deposited on fused silica substrates [79] and the zone model [7] proposed for these microstructures as well as those obtained either in our laboratory or reported by others for $\mathrm{In}_{2} \mathrm{O}_{3}: \mathrm{Sn}$ (ITO) $[10,11], \mathrm{SnO}_{2}: \mathrm{Sb}$ (ATO) [12,13], $\mathrm{TiO}_{2}$ [14], $\mathrm{ZnO}(\mathrm{ZO})$ and AZO [14]. The electrical properties of $\mathrm{ZnO}: \mathrm{Al}$ sol-gel films are then analyzed in terms of the parameters of this model and are discussed.

\section{Experimental}

The preparation of the different sols and the single and multilayer coatings described hereafter has been already reported $[8,10-14]$.

For our own data (ATO, AZO) the thickness of sintered dip-coated layers was controlled by varying the sol concentration and the withdrawal speed from a few nanometers to about $200 \mathrm{~nm}$ and determined after chemical etching using a stylus profilometer (Tencor P10). Multilayer films have been obtained by repeating the same coating procedure. The parameter called "single layer thickness" (SLT) used to characterize single layers is the real physical thickness. For multilayer films, SLT was calculated as $\mathrm{SLT}=d_{\text {Stylus }} / N$ where $d_{\text {Stylus }}$ is the total thickness of the stacks and $\mathrm{N}$ the number of layers deposited. Although the 
first layer was usually found slightly thicker than the subsequent ones, the procedure describes the different systems with reasonable accuracy.

The microstructure of the coatings has been determined using X-ray diffraction (Siemens D 500), X-ray reflectometry (X'Pert Philips or D500 Siemens) and cross sections of the coatings observed by transmission electron microscopy (CM 200 FEG, Philips). The crystallite size has been extracted from the X-ray data using Scherrer's equation [8]. They are average values that do not take into account possible variations through the coatings but they reflect however the influence of the different processing parameters (amount of doping, parameters of the deposition process and methods of sintering, etc.). The parameter called hereafter "intrinsic crystallite size" (ICS) is defined as the crystallite size determined for films much thicker than the crystallite size. The values for coatings taken from the literature are those determined from X-ray data or alternatively from an estimation of TEM images. For coatings presenting a columnar structure and for which no X-ray data has been determined on comparable thick single layer, the base diameter of the columns was taken as ICS.

In order to compare the different data sets, the resulting structures are described as a function of the ratio $q=\mathrm{ICS} /$ SLT. The sintering temperature is abbreviated with $T_{\mathrm{S}}$, whereas $T_{\mathrm{M}}$ stands for the melting temperature of the metal-oxide.

Electrical properties of ATO and AZO coatings have been determined at room temperature using the van der Pauw geometry and performing Hall measurements with a magnetic field of 1.4 T (MMR Technologies).

\section{Results and discussion}

\subsection{Morphology of coatings}

Taking AZO coatings as an example, four different morphologies have been observed depending on the $q$ value (Fig. 1).

A granular structure was expected for layer thickness larger than the crystallite size. However it was only found for all single and multilayer films when SLT $>2.4$ ICS $(q<0.42)$. A typical morphology of a single AZO layer is shown in Fig. 1 (top left). The coating was obtained using a concentrated sol $(0.47 \mathrm{~mol} / \mathrm{l})$ doped with 0.6 at. $\% \mathrm{Al}$, fired in air for $30 \mathrm{~min}$ at $600{ }^{\circ} \mathrm{C}$. The single layer thickness SLT is $156 \mathrm{~nm}$, the average crystallite size calculated from the (002) reflex is $41 \mathrm{~nm}$ so that $q=0.28$.

A layered structure was observed when $1 \cdot \mathrm{ICS}<\mathrm{SLT}<$ 2.4 ICS i.e. for $0.42<q<1$. An example is shown in Fig. 1 (bottom left) for a 5-layer $\mathrm{ZnO}: \mathrm{Al}$ coating made with a medium concentrated sol $(0.2 \mathrm{~mol} / \mathrm{l})$ containing 5 at.\% Al. Each layer was fired for $3 \mathrm{~min}$ at $550{ }^{\circ} \mathrm{C}$. The total thickness of the stack is $91 \mathrm{~nm}$, the SLT is $18.2 \mathrm{~nm}$ and the corresponding ICS is $15 \mathrm{~nm}$ so that $q=0.82$.
A columnar structure was observed in multilayer coatings when SLT $<$ ICS, i.e. when $q>1$. The crystallite sizes are larger or in the range of the thickness of each single layer. Such a morphology is shown in Fig. 1 (top right) for a 20-layer $\mathrm{ZnO}: \mathrm{Al}$ coating. The layers have been deposited using a low concentrated sol $(0.05 \mathrm{~mol} / \mathrm{l})$ doped with 0.6 at.\% aluminum and fired for $3 \mathrm{~min}$ at $450{ }^{\circ} \mathrm{C}$. The total thickness of the stack is $72 \mathrm{~nm}$, SLT is $3.6 \mathrm{~nm}$ and the crystallite size ( 002 reflex) is $26 \mathrm{~nm}$. The corresponding ICS is $26.5 \mathrm{~nm}$ so that $q=7.4$ The image shows characteristic dendritic shaped grains.

One of the AZO coatings presented a highly dense columnar-granular structure made of $10 \mathrm{~nm}$ grains arranged in columns (bottom right). It was produced by dipping 20 times with a low concentrated sol $(0.05 \mathrm{~mol} / \mathrm{l})$ with 5 at. $\%$ Al. Each layer was fired for $3 \mathrm{~min}$ at $550{ }^{\circ} \mathrm{C}$. The total thickness is $65.6 \mathrm{~nm}$ and the ICS is $15.2 \mathrm{~nm}$ resulting in $q=4.57$.

Additional information such as the density profile across the layers was obtained by fitting the X-ray reflectometry curves. The results are discussed in detail in $[7,9]$.

The results for all AZO and those obtained for the above mentioned coatings could be represented in a diagram where ICS is plotted versus SLT. The different structures lie in well separated regions limited by straight lines passing through the origin [7]. However, a more informative plot, commonly known as a structure zone model (SZM), was achieved when the ratio $q=\mathrm{ICS} / \mathrm{SLT}$ is plotted against the homologous temperature $T_{\mathrm{H}}=T_{\mathrm{S}} / T_{\mathrm{M}}$ (Fig. 2). In contrast to SZM's for PVD, $T_{\mathrm{S}}$ represents the sintering temperature and not the substrate temperature in this model.

All columnar structures (square symbols), layered structures (diamonds), granular structures (circles) and the columnar-granular structure (crossed square) are lying within the zone II $\left(0.3<T_{\mathrm{H}}<0.5\right)$ of the Movchan and Demchishin model, a region characteristic for PVD films with columnar grains separated by distinct intercrystalline boundaries [1]. Zone I of this model, consisting of tapered crystals with domed tops separated by voided boundaries, and zone III, characteristic of equiaxed grains with a bright surface, are not observed in sol-gel coatings. The sol-gel zone boundaries, however, depend essentially on the $q$ values. The columnar structure region, observed for sol-gel coatings made of thin single layers, is located at the top of the diagram where $q>1$. In PVD and CVD processing, the deposited layers grow continuously at a low rate. If a structure parameter $q$ had to be defined for such processes, its value would be high $(q \gg 1)$ as it would involve the ratio of an intrinsic crystallite size, ICS, to an instantaneous very small thickness, SLT. Our findings, therefore, are in agreement with those observed for coatings made by these processes. The observation of layered and granular structures in sol-gel processing for smaller $q$ values is particular interesting as these structures are not observed in PVD or CVD processing because of the too high value of $q$. The difference between sol-gel and PVD or CVD coatings is therefore quite understandable. 

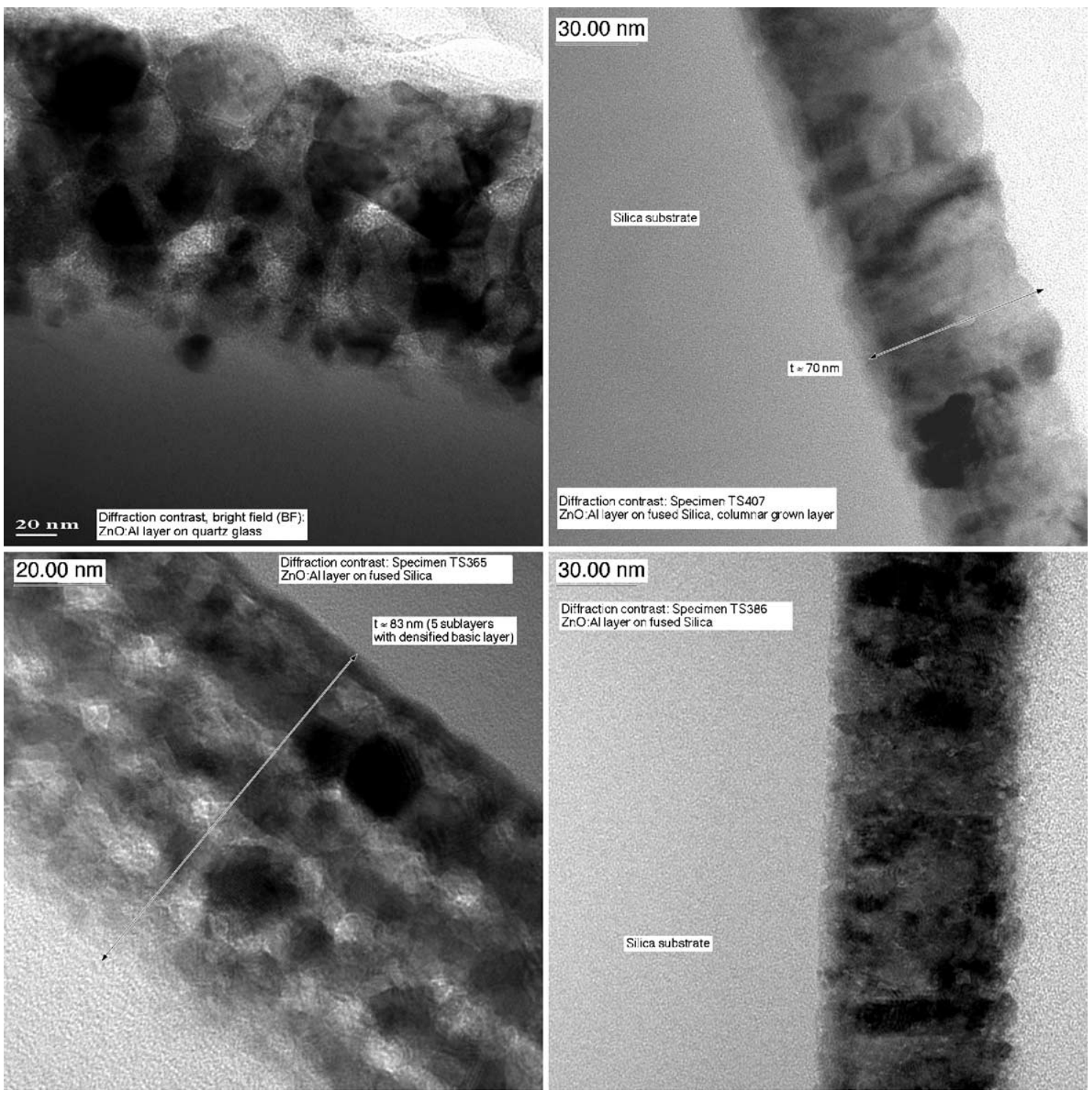

Fig. 1. TEM cross-sections of AZO layers dip-coated on fused silica substrates. Top left: Granular structure of a single layer. Sol: $0.47 \mathrm{~mol} / 1 \mathrm{with} 0.6$ at.\% Al content; withdrawal speed: $5 \mathrm{~mm} / \mathrm{s}$; drying: $10 \mathrm{~min}$ at $110{ }^{\circ} \mathrm{C}$; firing: $30 \mathrm{~min}$ at $600^{\circ} \mathrm{C}$. The total thickness is $156 \mathrm{~nm}$ and the crystallite size is $41 \mathrm{~nm} . q \quad 0.28$. Top right: Columnar structure of 20 layers. Sol: $0.05 \mathrm{~mol} / 1$ with 0.6 at. $\% \mathrm{Al}$; withdrawal speed: $1 \mathrm{~mm} / \mathrm{s}$; each layer was fired for 3 min at $450{ }^{\circ} \mathrm{C}$. The total thickness is $72 \mathrm{~nm}$, the crystallite size is $26 \mathrm{~nm}$, ICS is $26.5 \mathrm{~nm} . q$ 7.4. Bottom left: Layered structure (5 layers). Sol: $0.2 \mathrm{~mol} / 1$ with 5 at.\% Al; withdrawal speed: $1 \mathrm{~mm} / \mathrm{s}$; each layer was fired for $3 \mathrm{~min}$ at $550^{\circ} \mathrm{C}$. The total thickness is $91 \mathrm{~nm}$ and the ICS is $15 \mathrm{~nm} . q$ 0.82. Bottom right: Columnar granular structure of 20 layers. Sol: $0.05 \mathrm{~mol} / 1$ with 5 at.\% Al; withdrawal speed: $1 \mathrm{~mm} / \mathrm{s}$; each layer was fired for 3 min at $550{ }^{\circ} \mathrm{C}$. The total thickness is $65.6 \mathrm{~nm}$ and the ICS is 15 nm. $q$ 4.57.

Recently Polley and Carter [5] showed that for pure $\mathrm{ZnO}$ films produced by a combustion CVD process, an amorphous zone, corresponding approximately to the region labeled A in Fig. 2, could be observed for $\mathrm{T}_{\mathrm{H}}<0.3$ as well as a transition zone, extending towards the zone II and corresponding approximately to the region labeled $T$ in Fig. 2. Both boundaries were found to move to lower $T_{H}$ values when the concentration of the solution decreased. It is worth to remember that layered and granular structures have not been observed for $\mathrm{ZnO}$ films produced by combustion CVD [5] and that the zone III could not be reached because of the sublimation onset at $T_{H}=0.51$. On the other hand, in our model, a decrease in solution concentration leads to a decrease of the SLT value and consequently to an increase of the value of the structure parameter $q$. Therefore, the dotted lines shown in Fig. 2 indicate only a possible trend for sol-gel layers.

It is obvious that the physical reason for the presence of the observed structures lies in the takeover of homogeneous nucleation over the heterogeneous nucleation when the single layer thickness increases.

\subsection{Electrical properties of AZO coatings}

The resistivity of several $\mathrm{ZnO}: \mathrm{Al}$ sol-gel multilayer coatings prepared with various aluminum doping concen- 


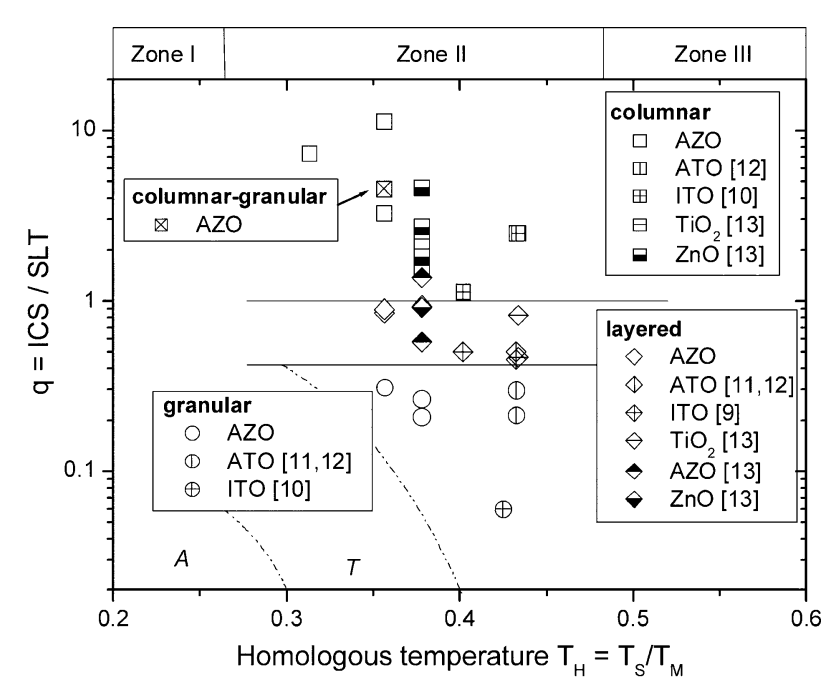

Fig. 2. Structure parameter $q$ of all investigated systems vs. the homologous temperature $T_{\mathrm{H}}$ [from [7]].

trations and sintered at a constant homologous temperature of $\mathrm{T}_{\mathrm{H}}=0.351$ is plotted versus the structure parameter $q$ in Fig. 3.

Although the parameter $q$ is certainly not the best physical parameter to correlate the electrical properties of TCO coatings, the plot clearly shows an overall trend of the resistivity data with increasing $q$ values: the granular structures have a high resistivity, that of layered structures is typically 10 times smaller and that of columnar structures is still lower, the lowest resistivity being obtained for the highest $q$ values $(q \geq 3)$. The decrease of the resistivity is correlated to the overall strong increase of the carrier mobility with the structure parameter $q$ from values as small as 0.2 for granular structures to about 25 to 40 for the columnar structures (Fig. 4) and a corresponding slight increase of the carrier concentration from about $3 \times 10^{19}$ (granular structure) to $10^{20} \mathrm{~cm}^{-3}$ (columnar structure) (Fig. 5).

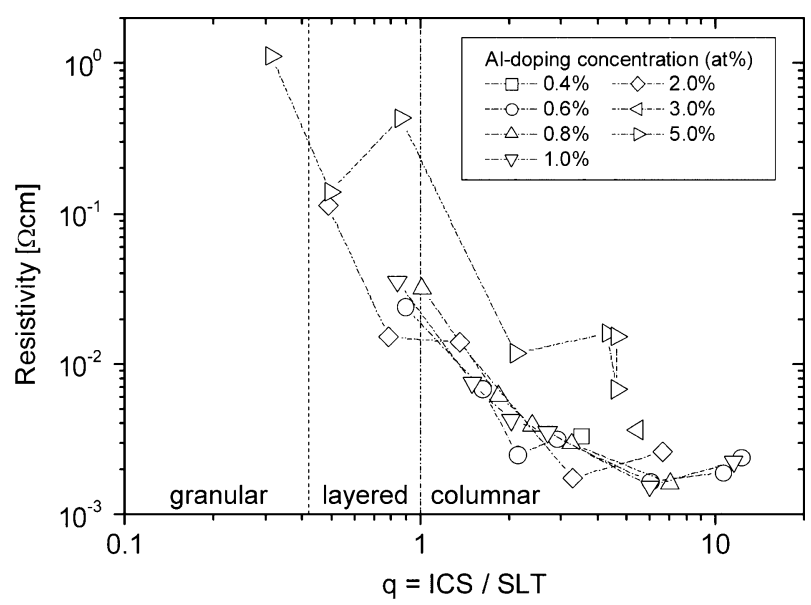

Fig. 3. Resistivity of $\mathrm{ZnO}: \mathrm{Al}$ films with different Al-doping concentration vs. structure parameter $q$. All layers have been sintered at $T_{\mathrm{H}} \quad 0.351$ during $3 \mathrm{~min}$.

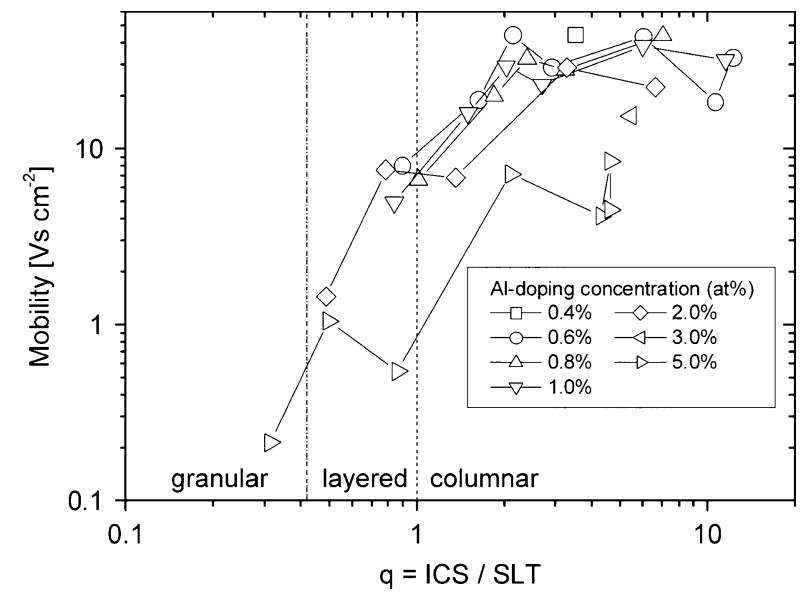

Fig. 4. Mobility of $\mathrm{ZnO}: \mathrm{Al}$ films with different Al-doping concentration vs. structure parameter $q$. All layers have been sintered at $T_{\mathrm{H}} 0.351$ during 3 $\min$.

Similar overall behaviour has been obtained for AZO coatings sintered at $\mathrm{T}_{\mathrm{H}}=0.266,0.287,0.308,0.330$, and 0.372 .

Such trends have also been found for sol-gel and nanoparticulate ITO coatings [15]. Stacks of thin multilayer sol-gel coatings sintered at $550{ }^{\circ} \mathrm{C}$ exhibited a columnar morphology with a low porosity ( $q \sim 2$ to 3 ) and a low resistivity $\rho=6 \cdot 10^{-4} \Omega \mathrm{cm}$ while thick single layers made with nanoparticles and sintered at the same temperature exhibited a granular structure $(q \approx 0.06)$ with a high resistivity $\rho=160 \cdot 10^{-4} \Omega \mathrm{cm}$.

These results outline the major drawback of wet chemical (e.g. sol-gel) processes for the production of low resistivity and low sheet resistance TCO coatings. These properties can only be obtained with a columnar structure and a value of $q \geq 3$. Such coatings are only achieved by depositing many $(\geq 10)$ very thin layers with sintering at high temperature. PVD and CVD processes achieved these properties in a continuous manner.

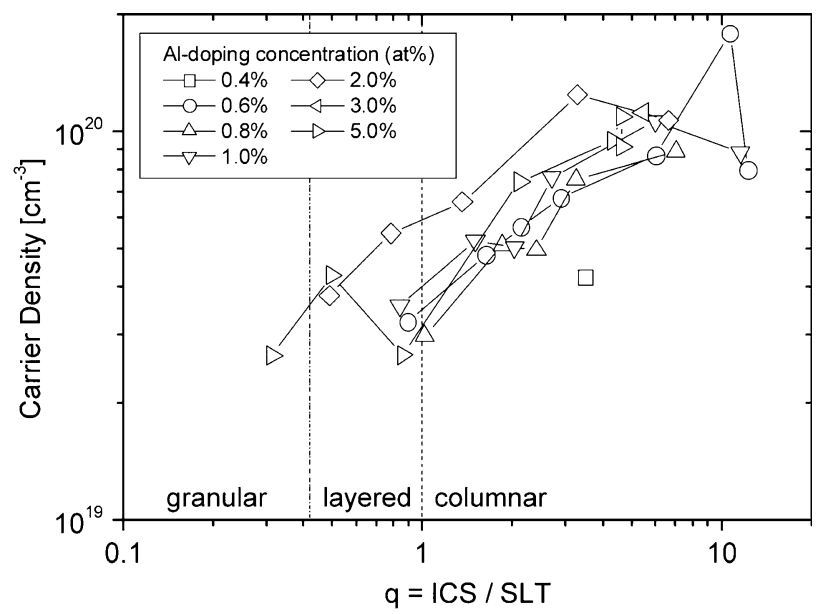

Fig. 5. Carrier concentration of $\mathrm{ZnO}: \mathrm{Al}$ films with different Al-doping concentration vs. structure parameter $q$. All layers have been sintered at $T_{\mathrm{H}} \quad 0.351$ during $3 \mathrm{~min}$. 
The resistivity of TCO coatings depends on the porosity of the coatings and is also influenced by electron scattering phenomena at the grain boundaries. High values of both parameters lead to an increase of the resistivity. An increase in porosity also signifies a decrease of the volumetric density, of the index of refraction and poorer mechanical properties. All these properties, therefore, could also be related to the parameters of the proposed structure zone model. However, systematic studies have not yet been reported.

\section{Conclusion}

Single and multilayer AZO, ATO, ITO, ZO and $\mathrm{TiO}_{2}$ sol-gel coatings may exhibit granular, layered or columnar structures. Their formation depends on several processing parameters which have been identified. Based on these observations, a three zone structure model is proposed to predict the microstructure of sol-gel coatings in terms of a structure parameter $q$, defined as the ratio of the intrinsic crystallite size to the single layer thickness and the homologous temperature, defined as the ratio of the sintering temperature to the melting temperature. The physical reason for the formation of those structures is the competition of homogeneous versus heterogeneous nucleation rates, which, in the sol-gel process, depend on the single layer thickness and the intrinsic crystallite size. The electrical properties (resistivity, mobility, carrier concentration) of $\mathrm{ZnO}: \mathrm{Al}$ transparent conducting oxide films prepared by the sol-gel process are strongly affected by the structure parameter.

\section{Acknowledgement}

The authors thank the State of Saarland and the Federal Ministry for Research and Education (Germany) for financial support.

\section{References}

[1] B.A. Movchan, A.V. Demchishin, Phys. Met. Metallogr. 28 (1969) 93.

[2] J.A. Thornton, Annu. Rev. Mater. Sci. 7 (1977) 239.

[3] R.A. Messier, P. Giri, R.A. Roy, J. Vac. Sci. Technol., A 2 (2) (1984) 500.

[4] P.-J. Kelly, R.D. Arnell, J. Vac. Sci. Technol., A 16 (5) (1998) 2858.

[5] T.A. Polley, W.B. Carter, Thin Solid Films 384 (2001) 177.

[6] B. Dumay, E. Finot, M. Theobald, O. Legaie, J. Durand, P. Baclet, J.P. Goudonnet, J. Appl. Phys. 92 (11) (2002) 6572.

[7] T. Schuler, T. Krajewski, I. Grobelsek, M.A. Aegerter, J. Sol-Gel Sci. Technol. 31 (2004) 235

[8] T. Schuler, M.A. Aegerter, Thin Solid Films 351 (1999) 125.

[9] T. Schuler, $\mathrm{PhD}$ thesis, Verdichtung und Kristallisation von transparenten leitfaehigen oxydischen Sol Gel-Schichten am Beispiel des Zinkoxids, INM and University of Saarland, Saarbrücken, Germany, (2003).

[10] Y. Takahashi, H. Hayashi, Y. Ohya, Mater. Res. Soc. Symp. Proc. 271 (1962) 401

[11] Y. Takahashi, S. Okada, R. Bel Hadj Tahar, K. Nakano, T. Ban, Y. Ohya, J. Non-Cryst. Solids 218 (1997) 129.

[12] M.A. Aegerter, A. Reich, D. Ganz, G. Gasparro, J. Pütz, J. Non-Cryst. Solids 218 (1997) 123.

[13] C. Goebbert, G. Gasparro, T. Schuler, T. Krajewski, M.A. Aegerter, J. Sol-Gel Sci. Technol. 19 (2000) 435.

[14] Y. Ohya, H. Saiki, T. Tanaka, Y. Takahashi, J. Am. Ceram. Soc. 79 (4) (1996) 825.

[15] N. Al-Dahoudi, M.A. Aegerter, in: J. Puetz, A. Kurz, M.A. Aegerter (Eds.), Proc. 5th International Conference on Coatings on Glass ICCG5, 2004, p. 585. 